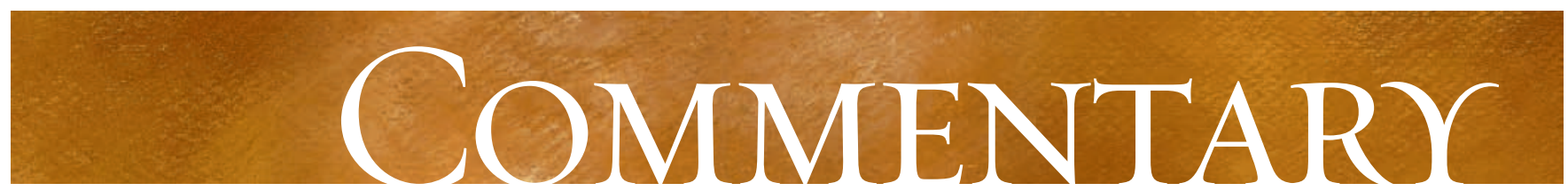

\title{
Obesity: the emerging cost of economic prosperity
}

\author{
Sonia S. Anand
}

$\infty \quad$ See related article page I07I

$\mathrm{W}$ estern countries are experiencing an epidemic of obesity and face increasing rates of related complications, including diabetes mellitus, elevated lipid levels and hypertension. Recently a World Health Organization Expert Consultation recognized that the definition of overweight and obesity may be different for Asian populations and recommended revised definitions. ${ }^{1}$ Their rationale was that Asian people experience type 2 diabetes and cardiovascular disease at a body mass index (BMI) lower than that of white people. Furthermore, a growing body of literature supports the notion that abdominal obesity may be superior to the BMI as a measure of obesity because of its association with diabetes and myocardial infarction is stronger than that of BMI, especially among non-white populations. ${ }^{2}$ Ethnic-specific thresholds for defining abdominal obesity have also been proposed. ${ }^{3}$ Altering the thresholds for overweight, obesity and abdominal obesity would predictably lead to an increase in the prevalence of these conditions in non-white populations.

Relatively few data on the prevalence of overweight and obesity are available from lower income or developing countries. In this issue (see page I07I), Jafar and colleagues ${ }^{4}$ report prevalence estimates from a large population-based sample of people over the age of 15 years in Pakistan using revised definitions of overweight and obesity (BMI $\left.\geq 23 \mathrm{~kg} / \mathrm{m}^{2}\right)$ and obesity $\left(B M I \geq 27 \mathrm{~kg} / \mathrm{m}^{2}\right)$. Unfortunately, they did not collect waist and hip circumferences. A cutoff BMI value of $23 \mathrm{~kg} / \mathrm{m}^{2}$ appears to be reasonable in their data set using receiver operating characteristic (ROC) curve analysis for conditions such as hypertension and diabetes. Their findings are concerning but not surprising: the prevalence of overweight and obesity was $25 \%$ and obesity $10 \%$ in the Pakistani study population. Examination of the age-specific prevalence of overweight and obesity also reveals worrisome trends: more than $40 \%$ of women and close to $30 \%$ of men aged $35-54$ years were classified as overweight or obese. This is concerning because overweight and obesity in middle-age are known risk factors for complications such as type 2 diabetes and cardiovascular disease, especially among people of South Asian origin. ${ }^{5}$

Jafar and colleagues also examined the determinants of obesity using a number of social variables, such as rural and urban dwelling, literacy and economic status, as well as some clinical and lifestyle factors, such as blood pressure, cholesterol and glucose concentrations, dietary intake and smoking status. Although the direction of association between these factors and outcomes cannot be discerned owing to the crosssectional study design, some important insights are apparent. The strongest predictors of overweight and obesity were societal factors, including urban living (odds ratio 2.20) and high economic status (odds ratio I.56). These factors raise the possibility that solutions required to reverse the rising prevalence of obesity must include societal reorganization, which would ultimately lead to decreased energy intake and increased energy expenditure by individuals.

\section{Although urbanization cannot be halted in most instances, it can be altered}

\section{to minimize its impact on} health.

Reliance on energy-saving devices such as cars and on sedentary behaviours such as television viewing and computer use increases with urban living and increasing socioeconomic status. Even though individuals who take on intensive and regular physical exercise may prevent weight gain, this lifestyle formula is not an effective solution for entire populations, since it requires a strong and long-term personal commitment in order to resist the powerful societal forces that promote obesity. Solutions that reach a large number of people are required and, before they can be implemented on a large scale, must be evaluated rigorously to ensure their effectiveness. Proposed changes to the structural environment, such as increasing street connectivity, adding bicycle paths, increasing public transportation, changing neighbourhood design to encourage walking and addressing safety concerns of parents for children, as a well as changes to the supply, pricing and availability of foods, have the potential of being among the most effective "mass solutions" to the problem.

Although health care workers and researchers are starting to recognize the powerful impact of societal forces on obesity, implementation of community-level interventions re- 
quires leadership at the local, provincial and federal levels of government. Unfortunately the goals of those concerned with disease prevention are often not aligned with the priorities of politicians, whose short-term goals appear to be more strongly aligned with economic prosperity and not on preventing adverse health consequences associated with increasing prosperity. Examples of successful collaborations between health care workers and governments include the "Trim and Fit Program" in Singapore, in which the ministry of health worked closely with the ministry of education to limit access to low-nutrition, energy dense snacks and beverages and to increase physical activity programs: the result was a reduction in obesity among youth. ${ }^{6}$

To implement and evaluate such changes in diverse environments requires 2 major changes: first, the formation of effective links between government at the local, provincial and federal levels with health care workers in order to ensure that health, and not short-term wealth, is at the top of their agendas and, second, adequate funding of research to evaluate which of these interventions are effective.

Economic prosperity and urban living carries with it some costs, which include overweight and obesity. Although urbanization cannot be halted in most instances, it can be altered to minimize its impact on health. Canada should play a leadership role in developing and evaluating community strategies to prevent and reduce overweight and obesity, especially in high-risk groups such as Aboriginal people, people of low socioeconomic status and suburban dwellers.

This article has been peer reviewed.

Sonia Anand is an Associate Professor of Medicine, McMaster University, Hamilton, Ont.

Competing interests: None declared.

\section{REFERENCES}

I. WHO Expert Consultation. Appropriate body-mass index for Asian populations and its implications for policy and intervention strategies [published erratum appears in Lancet 2004;363:902]. Lancet. 2004; 363:157-63.

2. Yusuf S, Hawken S, Ounpuu S, et al; INTERHEART Study Investigators. Obesity and the risk of myocardial infarction in 27000 participants from 52 countries: a case-control study. Lancet 2005;366:1640-9.

3. Alberti KG, Zimmet P, Shaw J; IDF Epidemiology Task Force Consensus Group. The metabolic syndrome - a new worldwide definition. Lancet 2005;366:1059-62.

4. Jafar TH, Chaturvedi N, Pappas G. Prevalence of overweight and obesity and their association with hypertension and diabetes mellitus in an Indo-Asian population. CMAJ 2006;175(9):I07I-7.

5. Razak F, Anand S, Vuksan V, et al; SHARE Investigators. Ethnic differences in the relationships between obesity and glucose-metabolic abnormalities: a crosssectional population-based study. Int JObes (Lond) 2005;29:656-67.

6. Toh CM, Cutter J, Chew SK. School based intervention has reduced obesity in Singapore. $B M J 2002 ; 324: 427$.

Correspondence to: Sonia S. Anand, 4 East, Rm. 44I, Hamilton General Hospital, 237 Barton St. E, Hamilton ON L8L 2X2; fax 905 577-I490; anands@mcmaster.ca 